\title{
Physical and Chemical
}

\section{Investigations of Ancient Ceramic,}

\section{Jordan}

Fadi Bala'awi, Firas Alawneh

Queen Rania's Institute of Tourism and

Heritage, The Hashemite University 


\section{Introduction}

Administratively, the territories of Transjordan (a neutral term for what is now Jordan) have always belonged to different provinces. During the Late Byzantine or Early Islamic periods, the administrative borderlines were imposed by geographic rather than political considerations. They were generally running from east to west (Hitti, 1970; Watson, 2001). Hence, we can distinguish three major regions in Transjordan: northern, central and southern. While the northern one certainly had privileged relations with north Palestine and Syria, the central region had close relations with Palestine, and the southern played an important role in relations with south Arabia and Egypt. In times of peace as well as in times of war, Transjordan has therefore played an important role as a platform for trade and warfare in both north-south and east-west directions.

It is quite possible that different patterns of cultural interactions simultaneously existed in Transjordan during this period. For instance, it can be postulated that change might have been much faster in the south than in the centre or north. In the south, one may also 
expect to see an enhanced interaction of the local culture with the Egyptian and South Arabian cultures, whereas in the northern area, a more complicated model of interaction might have been in place between the local culture and those of Palestine, Syria, Byzantium, and probably Sasanid Mesopotamia. Whether one wants to associate prosperity or decline with this historical transition (Schick, 1995; Walmsley, 2001; Watson, 2001; Whitcomb, 2001, cutting-edge evidence can certainly be provided by the scientific study of the material culture of the societies under consideration, and without having to suffer from a biased reading of these changes. Needless to say, the ceramic traditions of the Islamic World in general and of the Levant in particular, during these early times, have not yet received fair scientific attention meant to elucidate the role it had to play in later technological development. Therefore, the choice of Transjordan for the study of the ceramic of the Late Byzantine-Early Islamic transition period is being driven by this motivation and favored by the variation in the socio cultural landscape and well-contrasted geological/geographical settings of the selected regions. 
This transition period has never been systematically studied previously. Only a few studies regarding pottery analysis were carried out, both internationally and locally. The integration of geochemical, mineralogical and petrological data would be an effective and representative approach for characterizing ceramics and clay material. Chemical and/or mineralogical analyses of ancient ceramics aim, above all, at characterizing the products, determining their probable origins, and obtaining better knowledge of their fabrication techniques.

\section{Samples and Methodology}

The samples studied in this project consisted of archaeological ceramics sherds drawn from twelve sites situated in the three major geographical areas:

(1) northern, (2) central, and (3) southern (Fig. 1). The samples belonged to the transition period, dated from the middle of the $6^{\text {th }}$ to the middle of the $8^{\text {th }}$ century AD, and were collected in collaboration with the archaeologists who had excavated the sites. Twenty potsherds were considered the minimum sample size necessary to characterize a single site, but in some cases availability was limited by the quantity of artifacts 
recovered from the excavation. A primary criterion for selecting transition period sherds focused on the presence of vertical levels. Samples from the Late Byzantine and Early Islamic levels were incorporated into the study whenever it was possible. Due to the complexity of differentiating between the two levels, archaeologists tend to assign some of the samples to the 'transition' period rather than associating them with a specific dated level (Amr, 2005).

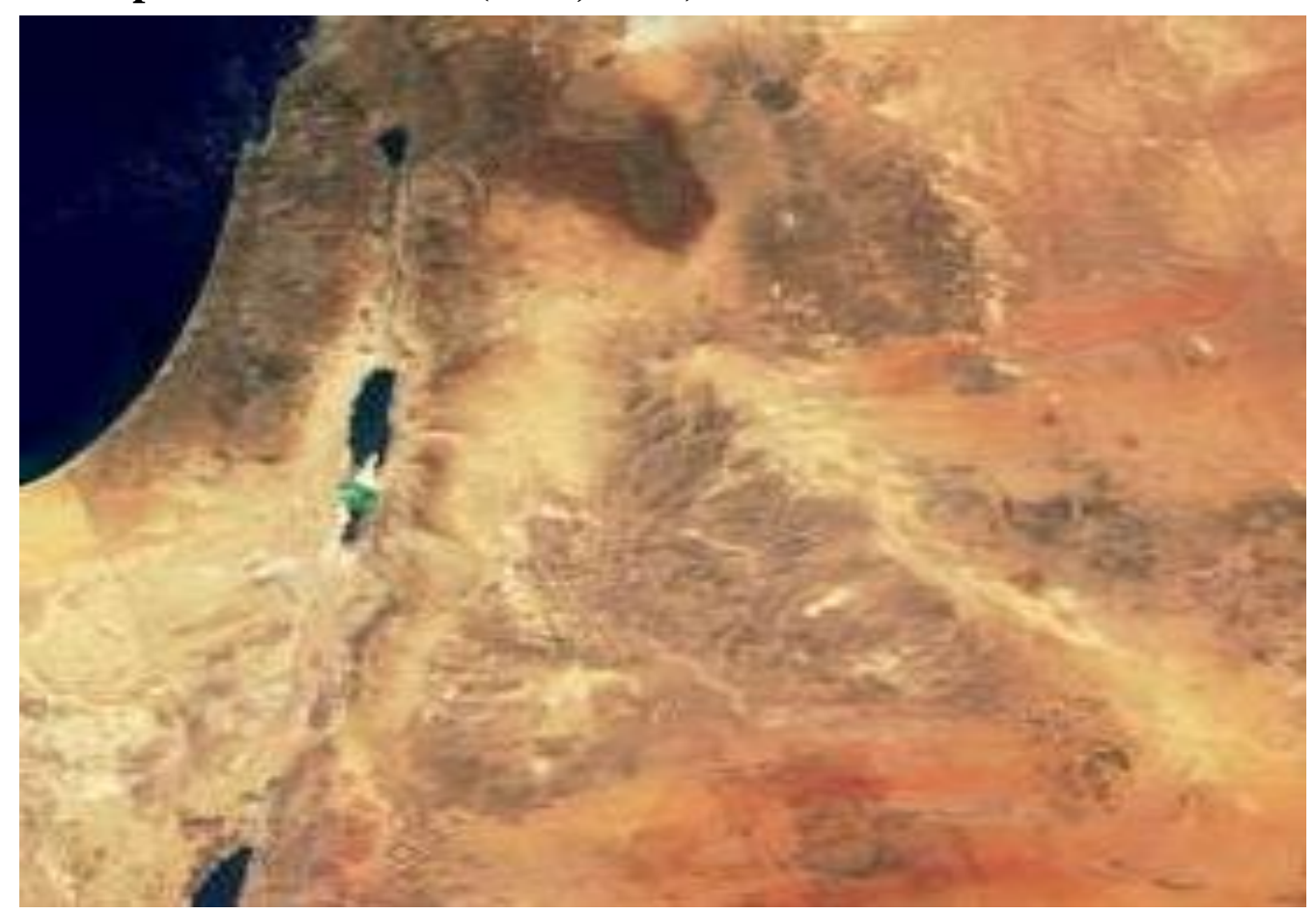

Fig. 1. Map of the Southern Levant with the archaeological sites selected for the study indicated by the sign $\odot$. 
A total of 228 samples were considered in this study (Table 1). Sherds included red, black, gray, yellow, pink, stamped, painted and glazed pottery. As part of the ceramic study, a program of analysis for clay materials collected in the proximity of the selected archaeological sites was also included. In total, eight clay samples were collected from the different geographical areas. These samples are being used for comparative purposes in order to identify possible source areas of the sherds. The collected clays were fired in oxidizing atmosphere at different temperatures, ranging from $500{ }^{\circ} \mathrm{C}$ to $1100{ }^{\circ} \mathrm{C}$. These firing experiments were used to define the technological characteristics of each clay material and compared with archaeological samples to further classify these ceramics according to their manufacturing technologies.

\section{Results and discussion}

The multifaceted analytical study of the pottery from Jordan generated different types of datasets. Compositional analysis with PIXE provided quantitative elemental compositions of the pottery and the clay materials. Phase analysis with XRD provided 
qualitative as well as semi-quantitative mineralogical compositions of the potsherds and allowed the technical study of the clay materials. Textural/morphological study with PLM of thin sections from representative samples provided information on the nature, amount, and grain size distribution of the inclusions, as well as the ceramic matrix.

In order to assess the validity of pottery classification, and better understand their fabrication technology, the ceramic sherds of three sites were characterized by XRD.

Observation of the diffraction patterns for samples from these sites reveals important similarities (Fig. 2) By reviewing the mineral assemblages in Table 1, and using petrographic results (Fig. 3), one can notice the similarity among them. Thus, for the different groups, the following results can be concluded: for instance, group Ia shows that the potter tended to add the same inclusion ratio $(\approx 50 \%)$ in samples FA102-JA and FA196-PE, or he might have used the same clay source, which had this natural distribution of inclusions. Inclusions in this group have the same size distribution and morphology (0.1-0.4 $\mathrm{mm}$ in size), are rounded to sub-rounded, and occasionally present some sharp edge 
grains. The phase analysis results for group Ia showed the same phases. For group Ib samples, the proportion of the inclusions is less than $23 \%$. The mineral assemblages are quartz, plagioclase, calcite, hematite, gehlenite, K-feldspar and pyroxene. Inclusions tend to have small size grains. Group II consisted of samples with the same dark matrix, and smaller inclusion ratio $(\approx 3 \%)$, with rounded to sub-rounded shape. The same technology appears to have been used on samples belonging to the same chemical group. This explanation could in turn be attributed to the hypothesis that people throughout the transition period kept the same trend and used almost the same technological aspect in ceramic manufacture. This conclusion was drawn for samples classified by archaeologists as belonging to the Early Islamic period or to the transition period. Unfortunately, none of the samples studied from this region can be ascribed with certainty to the Late Byzantine level. Thus, the previous conclusion concerns only the transition period and the Early Islamic finds.

The presence or absence of specific mineral phases in a ceramic product gives information on the production technology. For an initial clay material of given chemical and mineralogical composition, the mineral 
assemblage detected with XRD is strongly influenced by firing temperature and atmosphere (Philpotts and Wilson, 1994). An estimation of the firing temperature may therefore be carried out on the basis of the mineral assemblage, as the occurrence or absence of specific mineral phases, at a given bulk composition, provides constraints on the maximum firing temperature. It should be noted that the time and conditions of the firing process do not necessarily result in a mineral assemblage which is in a state of thermodynamic equilibrium, and this aspect must be remembered in any attempt to predict the firing conditions (Maggetti, 1982). However, a preliminary rough estimation of the firing temperature for each of the above mineral assemblages and an interpretation of the mineralogical composition are still useful as starting points. In order to explore this possibility, experiments were carried out on samples JA1-clay, JA2-clay, and PE-clay, from the Jarash and Pella sites areas see Fig. 4. The clay samples were fired under oxidizing condition over a large temperature range.

For Jarash clay, the original clay (JA1) contains the following phases: illite-montmorillonite, calcite, dolomite plagioclase and quartz. As temperature goes 
up and reaches $500{ }^{\circ} \mathrm{C}$, the illite-montmorillonite mixed layer is completely decomposed. At $600{ }^{\circ} \mathrm{C}$ and before the temperature reaches $600{ }^{\circ} \mathrm{C}$, dolomite and calcite

\begin{tabular}{|c|c|c|c|}
\hline Site Name & $\begin{array}{c}\text { Abbreviat } \\
\text { ion }\end{array}$ & $\begin{array}{c}\text { Geographical } \\
\text { location }\end{array}$ & Mineral assemblages \\
\hline Amman & $\mathbf{A M}$ & Middle & $\begin{array}{l}\text { Qz, PI, He, Ca, Il } \\
\text { Qz, PI, Ge, Kf }\end{array}$ \\
\hline Aqaba & $\mathbf{A Q}$ & South & $\begin{array}{l}\text { Qz, Pl, Ge, Py, He } \\
\text { Qz, Pl, He, Ge, Ca }\end{array}$ \\
\hline Beit Ras & BR & North & $\begin{array}{l}\text { Qz, Il, Pl, He } \\
\text { Qz, Pl, Ge, Ca, He }\end{array}$ \\
\hline Gharandal & GH & South & $\begin{array}{l}\text { Qz, PI, Ca } \\
\text { Qz, Py, Ge, PI, Kf }\end{array}$ \\
\hline Humaimah & HM & South & $\begin{array}{l}\text { Qz, Pl, Ca, Py, Ge } \\
\text { Qz, Ge, Pl, Ca, He }\end{array}$ \\
\hline Jarash & JA & North & $\begin{array}{l}\text { Qz, Pl, He, Ca } \\
\text { Qz, Di, Py, Ge, Pl, Kf }\end{array}$ \\
\hline Jericho & $\mathbf{J E}$ & Middle & $\begin{array}{l}\text { Qz, Pl, Kf, Il } \\
\text { Qz, Ge, Pl, He, Py }\end{array}$ \\
\hline $\begin{array}{l}\text { Khirbit El } \\
\text { Nawafleh }\end{array}$ & $\mathbf{K N}$ & South & $\begin{array}{l}\text { Qz, Pl, Ge, Py, He } \\
\text { Qz, PI, Ca, Il }\end{array}$ \\
\hline Madaba & MA & Middle & $\begin{array}{l}\text { Qz, Pl, Ca } \\
\text { Qz, Py, Pl, Di, Ge, }\end{array}$ \\
\hline
\end{tabular}




\begin{tabular}{|c|c|c|l|}
\hline Pella & PE & North & $\begin{array}{l}\text { Qz, PI, He, Ca, Il } \\
\text { Qz, PI, Di, Py, He }\end{array}$ \\
\hline Um Er Rasas & \multirow{2}{*}{ UR } & Middle & $\begin{array}{l}\text { Qz, Ge, Pl, Py, He } \\
\text { Qz, Ca, Il }\end{array}$ \\
\hline Um El Waleed & UW & Middle & $\begin{array}{l}\text { Cl, Ta, Do } \\
\text { Qz, Ge, Pl, Py, Kf, }\end{array}$ \\
\hline
\end{tabular}

Table 1 : List of archaeological sites included in the study area, their identified mineral assemblages and their respectivelocations Qz: Quartz, Di: Diopside, Py: pyroxene, Ge: Gehlenite, Pl: Plagioclase, Il: illite, He: Hematite, Ca: calcite.

peaks could still be seen, while at $700{ }^{\circ} \mathrm{C}$ and over the peaks were decomposed. When temperature reaches $800{ }^{\circ} \mathrm{C}$, illite peaks start to decompose and low firing phases are absent. The intensity of clay peaks decreases over $800{ }^{\circ} \mathrm{C}$ and disappears around $900{ }^{\circ} \mathrm{C}$. Over 900 ${ }^{\circ} \mathrm{C}$, new firing phases of pyroxene and hematite begin to crystallize. In addition, some primary phases also exhibit clear changes. Illite starts to undergo decomposition process that is completed between $850{ }^{\circ} \mathrm{C}$ and $900{ }^{\circ} \mathrm{C}$. In contrast, the illite (110) reflection is not essentially affected below $900-950{ }^{\circ} \mathrm{C}$ and is stable up to 1000-1050 ${ }^{\circ} \mathrm{C}$ (Maggetti, 1981). On the other hand, plagioclase shows an increasing intensity of the peaks 
that must be related to the crystallization of plagioclase minerals, anorthite and albite.

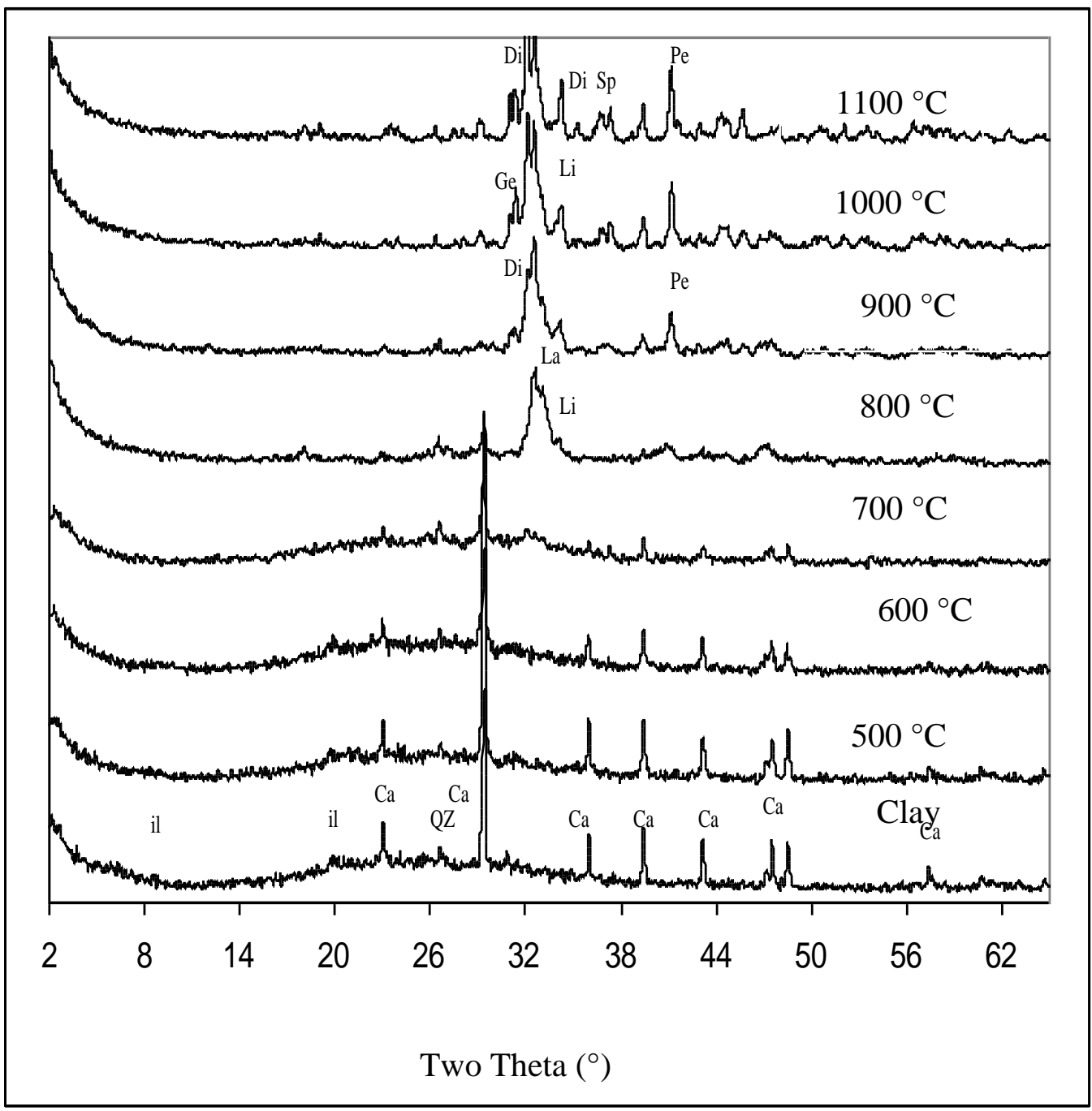

Fig.2. XRD patterns for PE-clay, fired at different temperatures range under oxidizing condition. The indicated mineral phases are: illite (II), quartz $(\mathrm{Qz})$, calcite $(\mathrm{Ca})$, lime (Li), gehlenite (Ge), and larnite (La). ), gehlenite (Ge), periclase (Pe), diopside (Di), spinel (Sp). 


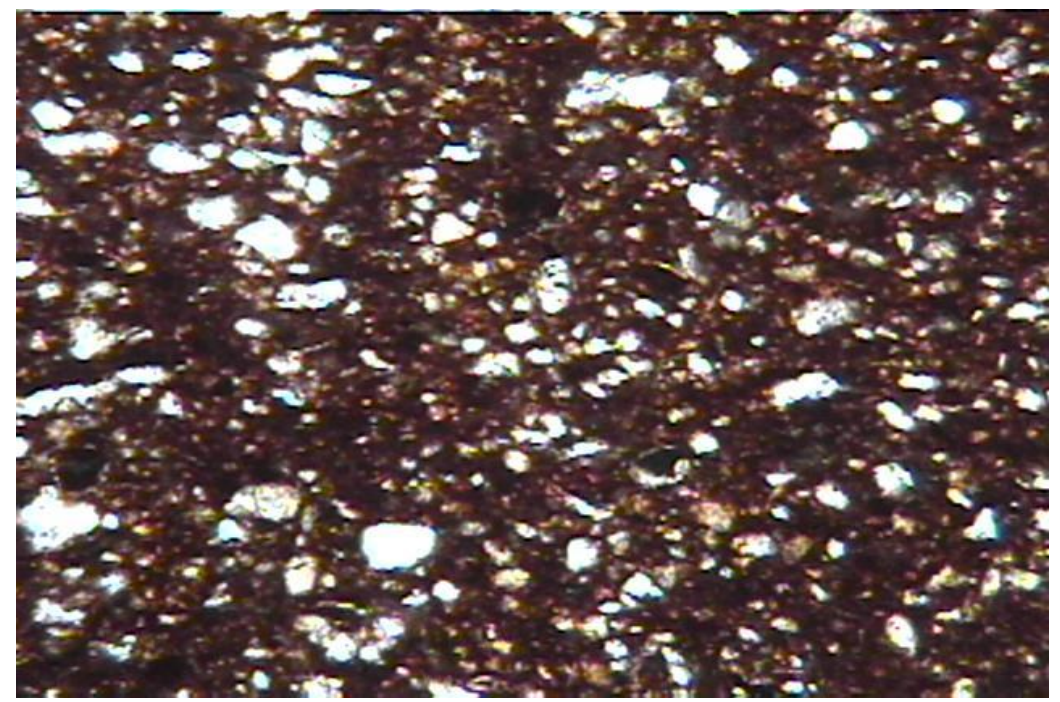

(b) FA102-JA

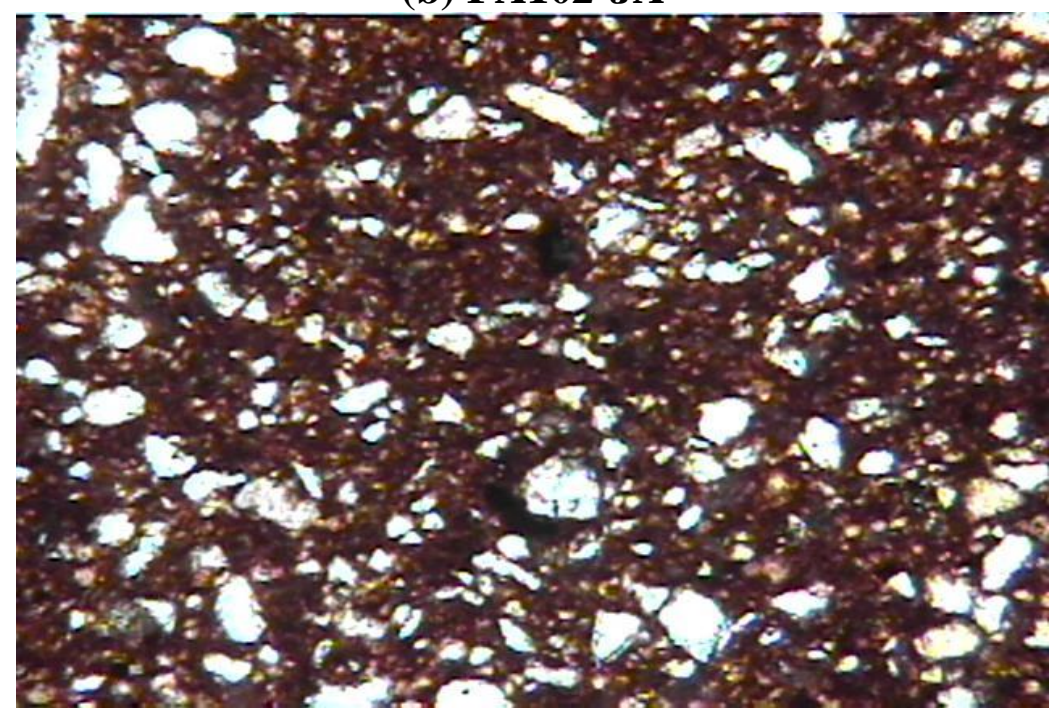

(a) FA196-PE

Fig. 3 Photomicrograph of sherds (a) FA196-PE, (b) FA102-JA showing quartz inclusion (50X magnification). 
Fig.4. A bar diagram of firing experiments carried out on JA1-clay, in oxidizing conditions with heating rate of $2^{\circ} \mathrm{C} /$ min, the indicated phases are: quartz; plagioclase; illite montmorillonite; illite, calcite, gehlenite; pyroxene; hematite; dolomite; and potassium feldspar, RT : room temperature. 


\section{Conclusion}

Overall, the technology employed seems to be very similar in the northern, central and southern regions. Pottery was made following roughly similar criteria, regardless of its domestic function. This can be regarded as a preliminary indication, provided by the analysis of mineralogical and petrographic data. Petrographic analysis, for instance, shows the presence of similar inclusions in samples of the same chemical groups.

The combination of chemical, phase, and petrographic analyses is an adequate approach to the characterization of archaeological ceramics. Measurement of major and minor element concentrations proved satisfactory in this case for establishing similarities and differences among sherds and clays. Using a variety of graphical and multivariate statistical methods, it has been possible to distinguish between samples from different sites with varying degrees of success.

Based on these analytical results, one can draw a number of preliminary conclusions on the nature of raw materials employed, ceramic technologies, distribution 
of products, and hence on the implicit socio-cultural and economic exchange trends within Transjordan during that period. The conclusions are being drawn for the individual sites and geographical regions, and for adjacent regions as well.

Based on the mineral assemblages observed with XRD and the color of the sherds, it is concluded that potters of the two groups favored firing in oxidizing atmosphere. Firing temperatures varied from about 700 ${ }^{\circ} \mathrm{C}$ to $900{ }^{\circ} \mathrm{C}$ for Beit Ras samples, from $800{ }^{\circ} \mathrm{C}$ to 1000 ${ }^{\circ} \mathrm{C}$ in Jarash, and $800{ }^{\circ} \mathrm{C}$ to higher than $1000{ }^{\circ} \mathrm{C}$ in Pella. However, a slight difference between the production technologies used for the two groups has been noticed. It consists of variation in ceramic thickness. Samples 188, 189 and 190 were thick ceramics, while samples from the other group were thinner. 


\section{References}

1. Amr, K., 2005. Personal communication.

2. Hitti, P.K., 1970. History of the Arabs: from the Earliest Times to the Present. $10^{\text {th }}$ Ed., MacMillan St. Martin's Press, London.

3. Maggetti, M., 1981. Composition of Roman pottery from Lousonna (Switzerland), in Scientific studies in ancient ceramics (ed. M. J. Hughes), 33-49, British Museum Occasional Paper 19, London.

4. Maggetti, M., 1982. Phase analysis and its significance for technology and origin. In: Olin JS, Franklin AD (eds) Archaeological ceramics. Smithsonian Institution, Washington, pp 121-133.

5. Philpotts, A.R.,Wilson, N., 1994. Application of petrofabric and phase equilibria analysis to the study of a potsherd, Journal of Archaeological Science, 21, 60718.Schick, R., 1995. The Christian Communities of Palestine from Byzantine to Islamic Rule: a historical and archaeological study. The Darwin Press, Inc., Princeton, NJ

6. Walmsley, A., 2001. Fatimid, Ayyubid and Mamluk Jordan and the Crusader Interlude. In: The 
Archaeology of Jordan, MacDonald, B. et al (Eds.), 515559.

7. Watson, P., 2001. The Byzantine Period. In: The Archaeology of Jordan. MacDonald, B. et al (Eds.), 461502.

8. Whitcomb, D., 2001. Umayyad and Abbasid periods. In: The Archaeology of Jordan. MacDonald, B. et al (Eds.), 503-513. 